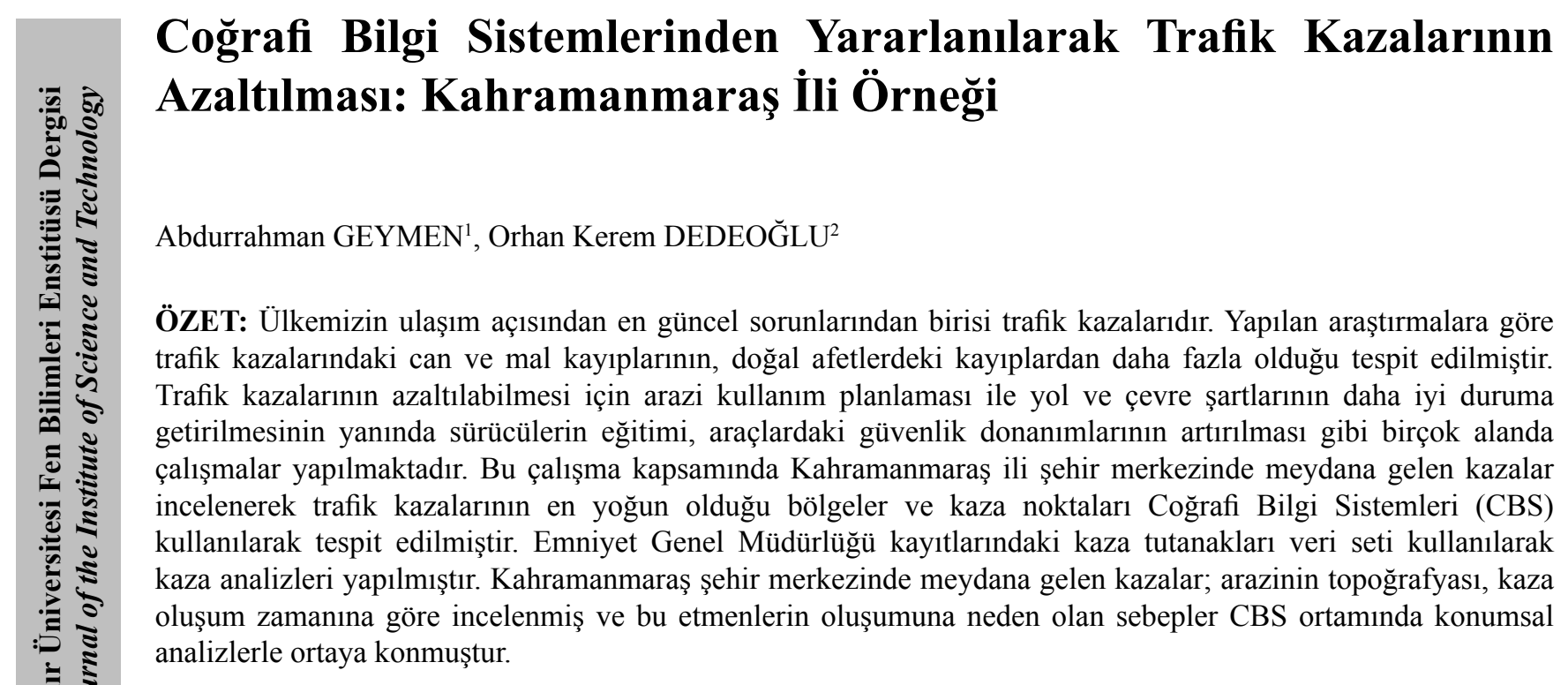

Anahtar Kelimeler: Coğrafi Bilgi Sistemleri, konumsal analizler, trafik kaza analizi

\title{
Reducing Traffic Accidents Using Geographical Information Systems: Kahramanmaras Case Study
}

\begin{abstract}
One of the most important problems of our country in terms of transportation is the traffic accidents. According to the studies on this issue, it has been determined that the loss of lives and properties in traffic accidents is higher than those in natural disasters. In order to minimize the number of traffic accidents, besides land use planning and improving the road and environment conditions, there are also many studies such as training the drivers, increasing the safety equipment in vehicles, and etc. Within the scope of this study, by examining the traffic accidents that have occurred in city center of Kahramanmaraş, the regions with highest accident frequency and the accident points were determined by using Geographical Information Systems (GIS). Traffic accidents were analyzed by utilizing the dataset obtained from police accident records provided by General Directorate of Security. Traffic accidents in Kahramanmaraş city center were investigated from the aspects of the type of accidents, the topography of land, and the time of accident, and then the factors that led to the formation of black spots were demonstrated by the spatial analysis in the GIS.
\end{abstract}

Keywords: Geographical Information System, spatial analyses, analysis of traffic accidents

Erciyes Üniversitesi, Mühendislik Fakültesi, Harita Mühendisliği Bölümü, Kayseri, Türkiye

Kahramanmaraş Büyükşehir Belediyesi, İmar Müdürlüğü, Kahramanmaraş, Türkiye

Sorumlu yazar/Corresponding Author: Abdurrahman GEYMEN, ageymen@erciyes.edu.tr 


\section{GíRIş}

Günümüzde hızlı, plansız kentleşme ve yanlış ulaşım politikaları nedeni ile trafik kazaları ülkemizin en güncel problemlerinden biri olmuştur (Saplıoğlu ve Karaşahin, 2005). Bu güncel problemlerin çözülmesinde ve alternatif ulaşım planlarının yapılmasında, yöneticilere yardımcı olmak amacıyla gelişen teknolojilerden yararlanmak, daha hizlı ve doğru sonuçlara götürecektir (Büberci, 1995). Büyükşehirlerde ulaşım alternatiflerinin azlığı ve aşırı ulaşım yoğunluğu nedeniyle yaya ve taşıt trafiğinde normalin üzerinde bir kullanıma sebep olmaktadır (Saplığlu ve Karaşahin, 2006). $\mathrm{Bu}$ durum taşıt trafiğinin birçok noktada kesişiyor olması nedeniyle yaya ve taşıt güvenliği açısından kaza riskini artırmaktadır. Trafik kazaları neticesinde her yıl binlerce kişi ölüm ve yaralanmalara bağlı olarak hayatını kaybetmektedir (Erdoğan, 2003). Trafik kazaları ailelerin yok olmasına veya ömrünün geri kalan bölümünü engelli olarak sürdürmek zorunda kalanlar bireyler oluşmasına sebep olmaktadır. Trafik kazaları sonucu meydana gelen maddi hasar ülke ekonomisini negatif yönde etkilemektedir (Karaşahin ve Terzi, 2002; Saplıoğlu ve Karaşahin, 2005).

Türkiye'de trafikkazalarınınhergeçen günartmasının temel nedenlerinin en başında hem disiplinler arası yaklaşımlarda hem de kurumlar arası yaklaşımlarda saptanması gereken arazi kullanım planlarının tam olarak hayata geçirilememesi ve problemin çözümünde bilimsel ve mühendislik çalışması gerektiğinin kavranamamış olmasıdır (Özgan, 2007). Karayolunun özelliği, yolun arazi kulanım yapısına uygunluğu, sürücü davranışları, araç ve çevresel faktörler, trafik kazalarının meydana gelmesinde rol oynayan en temel faktörlerdir (Bilim, 2006; Özgan, 2007).

Trafik kazalarının azaltılması için dünyada birçok teknik ve bilimsel araştırmalar yapılmaktadır. Bu araştırmalar yapılırken kaza nedenleri belirlenmekte ve bu nedenlere göre tedbir alınmaktadır. Kazalara sebep olan nedenlerin hızlı ve doğru olarak tespit edilmesi, çözümüne yönelik önleyici tedbirlerin alınmasını sağlayacaktır (Mandloi and Gupta, 2003; Tuncuk, 2004). Bilgi teknolojilerinin en çok kullanıldığı alanlardan biri olan Coğrafi/Kent Bilgi Sistemleri (CBS/ KBS) bu tür kazalara neden olan sebepleri belirleyen ve önleyici tedbirlerin alınmasına yönelik stratejik planlamaların geliştirilmesine katkı sağlayan bilgisayar destekli sistemlerdir. CBS, yerleşim alanlarının planlamasında başta olmak üzere ve farklı birçok disiplinler tarafindan yaygın olarak kullanılmaktadır. CBS, konuma dayalı gözlemlerden elde edilen grafik ve grafik olmayan bilgileri organize eden, depolayan, sorgulayan ve analiz eden ve sonuçlarını bir bütün olarak kullanıcıların imkanına sunan sistemler bütünü olarak tanımlanmaktadır (Foote and Lynch 1996; Geymen ve Yomralığlu, 2006).

Kent Bilgi Sistemleri (KBS) ise, kente ait bilgilerin toplanması, veriler arasındaki ilişkilerin kurulması ve analizlerin yapılarak kentin her türlü ekonomik, sosyal, kültürel, idari ve diğer hizmetlerinin en iyi şekilde gerçekleştirilmesini sağlamak amacı ile gerçekleştirilen CBS'nin kent bazında bir uygulamasıdır (Bensghir ve Akay, 2006).

Literatürde CBS/KBS teknolojileri kullanılarak trafik kazalarının önlenmesine yönelik birçok yerli ve yabancı çalışma bulunmaktadır (Camkesen, 1998; Korkmaz, 2005; Söylemezoğlu, 2006; Mirasyedi, 2006; Bek, 2007; Çiçek, 2007; Özgan, 2008; Erdoğan ve ark., 2008; Tortum ve ark., 2012). Çodur ve ark., (2013) yılında yapmış olduğu çalışmada, karayolu güvenliğinin sağlanmasında kazalara neden olan faktörlerin incelenmesi ve Genelleştirilmiş Lineer Regresyon tekniği ile kaza tahmin modelinin oluşturulması hedeflenmiştir. Ertunç ve Çay (2013) yılında yapmış olduğu çalışmasında CBS yardımıyla Antalya İl Merkezi'nde 2009 ve 2010 yıllarında meydana gelen ölümlü-yaralanmalı karayolu kavşak kazalarının istatistiksel değerlendirmelerini yaparak kazaların hangi faktörlerden etkilendiği belirlenmiştir. Gündoğdu (2010) yılında yapmış olduğu çalışmada Adana ili şehir merkezinde meydana gelen kazalar Emniyet Genel Müdürlügünden temin edilen kaza tutanakları incelenerek trafik kazalarının yoğun olduğu bölgeler CBS kullanılarak tespit edilmiştir. Trafik kaza tespit tutanaklarında yer alan bilgiler kullanılarak CBS'nin kaza analizinde etkinliği ortaya konarak Çekirdek Kestirimi Yöntemi ile kaza yoğunluk tahmini yapılmıştır. Erdoğan (2008) yaptığı çalışmada; Afyonkarahisar şehrinde 1996-2006 yıllarında meydana gelen kazaları CBS kullanarak kazaların olduğu kara noktaların belirlenmesinde, Poison testi ve Kernel Density Analiz metodunu kullanmıştır. Analizler sonucunda kazaların yaz ve kış aylarında fazla olmakla beraber ölümle sonuçlananların ise genelde geceleri meydana geldiği tespit edilmiştir. Özgan (2008) tarafından yapılan çalışmada ise, kazaya karışan araç tipleri ve kazaların oluş şekli ile kaza sonuçları arasındaki ilişkiler analiz edilmiştir. Elde edilen veriler tablo haline getirilmiş ve Statistical Package for the Social Science (SPSS) programı kullanılarak çoklu lineer regresyon analizleri yapılmıştır. Araç tipi ile 
ölümlü kazalar arasındaki ilişkide, 0.49 ilişki düzeyiyle kamyonet birinci sırada ve 0.43 ile kamyon ikinci sırada yer alırken 0.21 ile otobüs son sırada yer almıştır.

$\mathrm{Bu}$ çalışmada; CBS yardımıyla Kahramanmaraş kent merkezinde 2012 ve 2013 y1llarında meydana gelen kazaların genel istatistiksel değerlendirilmesi yapılarak kazaların hangi faktörlerden etkilendiği tespit edilmiştir. Kahramanmaraş kent merkezinde en fazla trafik kazalarının meydana geldiği bölgeler belirlenerek kaza kara noktalarının tespiti yapılmıştır. Belirlenen bölgelerde, 2013 y1lında en fazla kaza gerçekleșen kaza bölgeleri sıralanarak, en fazla kazanın gerçekleştiği ilk 11 bölge araştırma kapsamına alınmıştır. Bu bölgelerde kazaya sebep olan unsurlar araştırılıp değerlendirilmiştir. Meydana gelen trafik kazası miktarlarının nasıl azaltılabileceği konusu üzerinde araştırmalar yapılarak elde edilen sonuçlara göre çözüm önerileri getirilmiştir.

\section{MATERYAL VE YÖNTEM}

Kaza tutanakları kullanılarak, kazaların oluş şekilleri, ölüm ve yaralanma bilgileri ve kaza yerinin fiziki özellikleri gibi bir takım bilgiler elde edilmektedir. CBS'leri kullanılarak kaza yerinde elde edilen bu bilgilerden yola çıkılarak kaza kara noktaların tespit edilmektedir. Kara noktaların tespiti için literatürde uygulanan birçok yöntem bulunmaktadır. En çok tercih edilen konumsal analiz yöntemleri Kernel Density ve
Hot Spot Analizleridir. Bu analiz yöntemlerinde önemli olan kritik kaza sayısını tespit etmektir (Saplığ lu ve Karaşahin, 2005). Ülkemiz için bu değer, kaza sayısı 3 olan değer olarak tespit edilmiştir (Kahramangil ve Şenkal, 1999)

\section{Çalışma Alanı}

Kahramanmaraş ili coğrafi konum olarak İç Anadolu, Doğu Anadolu, Güneydoğu Anadolu ve Akdeniz bölgelerinin birleştiği noktada yer almaktadır. $14.346 \mathrm{~km}^{2}$ 'lik yüzölçümü ile Türkiye'nin 11. büyük vilâyeti durumundadır. $37^{\circ}-38^{\circ}$ kuzey paralelleri ile $36^{\circ}-37^{\circ}$ doğu meridyenleri arasında yer alır. Merkez ilçe deniz seviyesinden $568 \mathrm{~m}$. yükseklikte olup, ilin kuzey kesimleri dağlıktır (Şekil 1).

\section{Veri Hazırlama ve Ön İşlemler}

Kahramanmaraş İl Emniyet Müdürlüğü ile yapılan yazışma ve görüşmeler neticesinde, Kahramanmaraş ilinde meydana gelen trafik kazalarına ait bilgiler Microsoft Excel formatında talep edilmiştir. Talep edilen veri setinde kaza tarihi, kaza saati, kaza yeri, ölü sayısı, yaralı sayısı ve hasar miktarı bilgileri bulunmaktadır. Veri setinde CBS'nin temelini oluşturan, nokta, çizgi ve poligon vektör formatları ile uydu görüntüsü raster veri formatı kullanılmıştır. Nokta veri formatını, kaza yerleri ve numarataj bilgileri, çizgi veri formatını cadde, sokak ve kavşak bilgileri, poligon veri formatını ise mahalle verileri oluşturmaktadır.

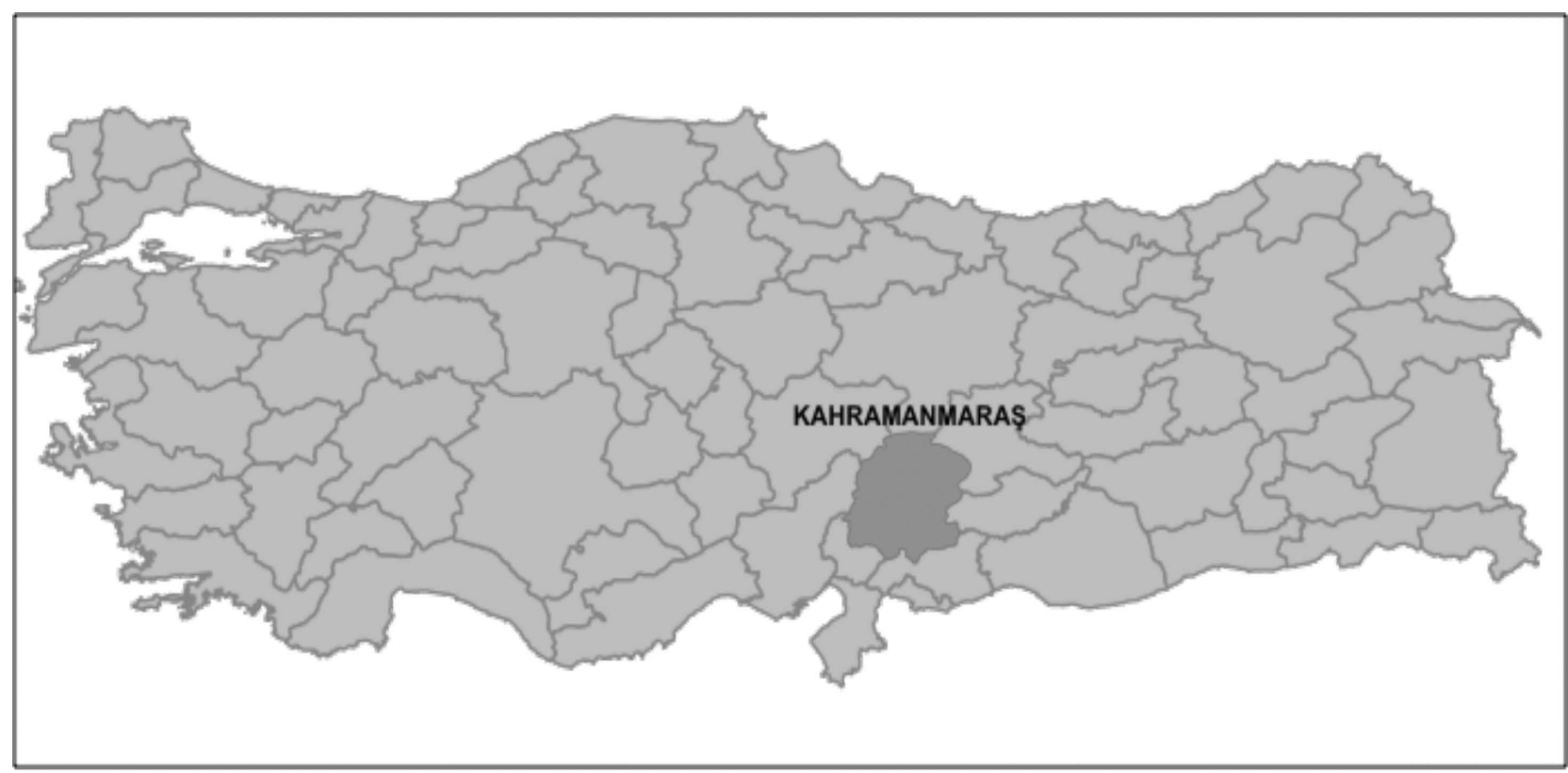

Şekil 1. Kahramanmaraş il haritası 
ArcGIS $\quad 10.3$ yazilımı kullanılarak, Kahramanmaraş il merkezindeki, mahalle, cadde, sokak, kavşak, numarataj ve uydu görüntülerine ait ham bilgiler CBS'ye aktarılmıştır. Bu bilgiler, Kahramanmaraş Büyükşehir Belediyesi, İmar ve Şehircilik Daire Başkanlığ 1 Harita Şube Müdürlüğünden temin edilmiştir. Altlık verilere UTM Projeksiyon, ED50 Datumu $3^{\circ}$ koordinat sisteminde projeksiyon tanımlaması yapılmıştır. Trafik kaza yerlerinin tespiti için, mahalle, yol ve numarataj bilgilerine göre arama yapılarak, nokta veri setinde trafik kaza noktaları ArcGIS yazılımında güncellenmiştir. Neticede, tutanaklarda belirtilen 2012 yılına ait ölümlü ve yaralanmalı gerçekleşen 963 kaza, maddi hasarlı gerçekleşen 810 kaza, 2013 y1lına ait ölüm yaralanmalı gerçekleşen 910 kaza ve maddi hasarlı gerçekleşen 863 kazada uygulanmıştır.

Toplamda gerçekleşen 3546 kazanın vektör format1 haline getirilmesi işleminden sonra, trafik kaza bilgilerine ait öznitelik tablolarında yer alan bilgilerde sorgulama ve analizler yapmak için düzenlemeler yapılmıştır.

\section{BULGULAR VE TARTIŞMA}

Kahramanmaraş ili şehir merkezinde 2012-2013 yıllarında meydana gelen yaralanmalı, ölümlü ve maddi hasarlı kazaların, kaza oluş yeri, kaza oluş zamanı ve arazinin topoğrafyasına göre incelenmesi yapılmıştır. Kaza sebep ve sonuçlarına göre oluşturulan veri tabanından sorgulama ve analizler yapılarak kazaların meydana geldiği yerler tespit edilmiştir. Sorgulama sonuçları grafik ve öznitelik tabloları olarak haritalar üzerinde gösterilmiştir.

\section{2 ve 2013 Yıllarında Meydana Gelen Kazalar}

Veri setinde yapilan sorgulamalar sonucunda; 2012 yılında caddelerde 942, caddelere bağlı kavşaklarda 615 ve sokaklarda 237 kaza gerçekleşmiştir. 2013 yılında ise caddelerde 980, caddelere bağlı kavşaklarda 548 ve sokaklarda 265 kaza gerçekleşmiştir (Şekil 2).

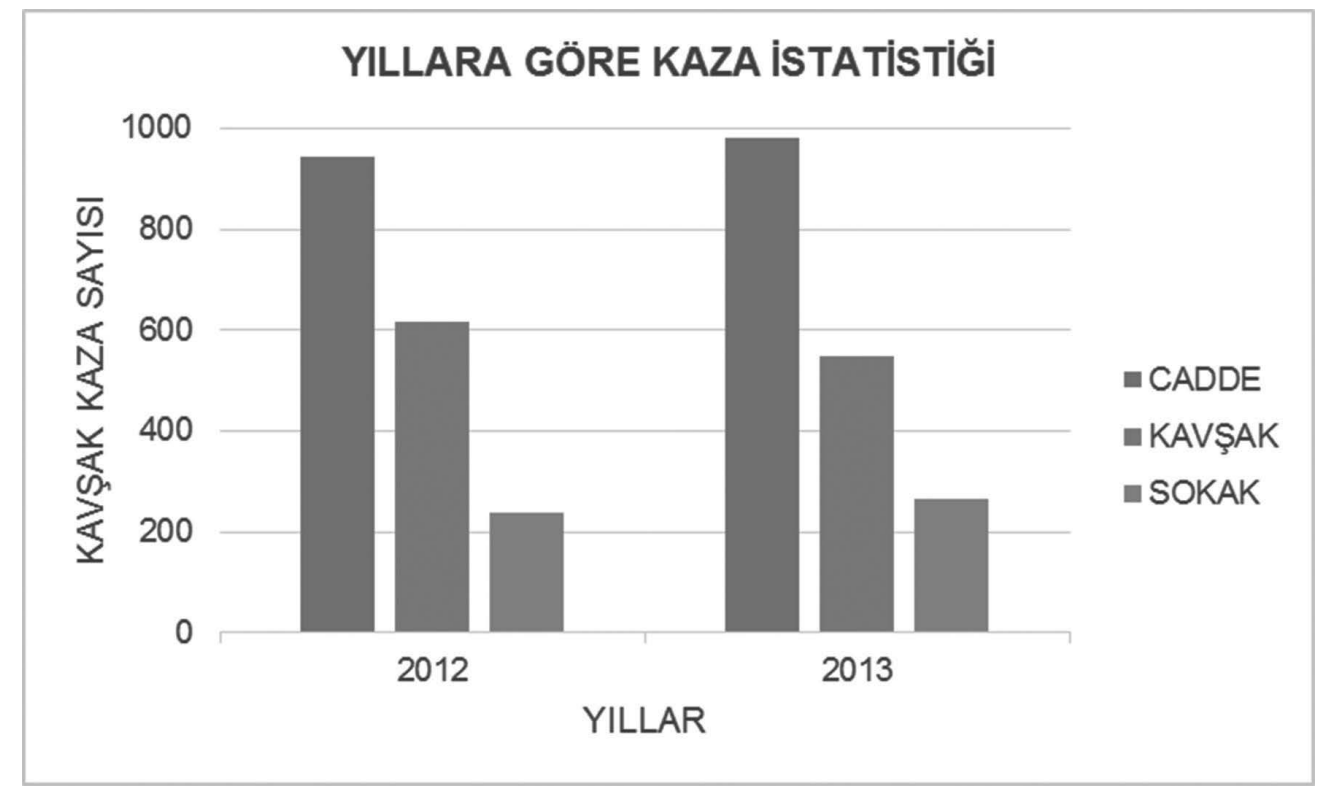

Şekil 2. 2012 ve 2013 yıllarında meydana gelen trafik kazaları

2012 ve 2013 y1llarında meydana gelen trafik kazalarının, Kahramanmaraş il merkezindeki cadde, kavşak ve sokakları dikkate alındığında, 202 caddede, 109 kavşakta ve 302 sokakta gerçekleştiği tespit edilmiştir. Aynı yerde 3' ten fazla gerçekleşen trafik kazaları, kaza kara noktası olarak tanımlanmıştır. Kahramanmaraş il merkezindeki cadde, kavşak ve sokaklarında gerçekleşen kazaların, kaza kara nokta sayısı tespiti yapılmış ve Çizelge 1 'de gösterilmiştir. 
Çizelge 1. 2012 ve 2013 yıllarına ait kaza kara noktaları

\begin{tabular}{|l|c|c|c|c|c|}
\hline Kaza Bölge Adı & $\begin{array}{c}\text { Kaza Gerçekleşen Bölge } \\
\text { Sayısı }\end{array}$ & $\begin{array}{c}\mathbf{2 0 1 2} \text { Kaza } \\
\text { Sayısı }\end{array}$ & $\begin{array}{c}\mathbf{2 0 1 3} \text { Kaza } \\
\text { Sayısı }\end{array}$ & $\begin{array}{c}\mathbf{2 0 1 2} \text { Kaza } \\
\text { Kara } \\
\text { Noktası }\end{array}$ & $\begin{array}{c}\mathbf{2 0 1 3} \text { Kaza } \\
\text { Kara Noktası }\end{array}$ \\
\hline CADDELER & 202 & 942 & 980 & 72 & 77 \\
\hline KAVŞAKLAR & 109 & 615 & 548 & 63 & 56 \\
\hline SOKAKLAR & 302 & 237 & 265 & 7 & 5 \\
\hline
\end{tabular}

Kahramanmaraş ili şehir merkezindeki kavşaklarda, 2012 yılında 615 kaza olmuş ve 63 kaza kara noktası bulunmaktadır. 2013 yılında ise 548 kaza olmuş ve 56 kaza kara noktası tespit edilmiştir. Kahramanmaraş il merkezindeki kavşaklarda meydana gelen bu kaza kara noktaların dağılımı Şekil 3'de gösterilmiştir.

Şekil 4, 5 ve 6'da, 2012-2013 yılları arasındaki verilerin, kaza yoğunlukları açısından karşılaştırıldığ zaman benzer özellikler gösterdiği, özellikle 2013 yılındaki kaza yoğunluğu haritasında şehrin bat1 kısmında kaza yoğunluğunun arttığı gözlenmektedir. $\mathrm{Bu}$ durumun en önemli sebebi şehrin batı yönünde gelişiyor olması, üniversitenin batıya taşınması ve batı yönünde inşa edilen resmi kurumlar için açılan yeni yolların trafik yoğunluğunu artırdığ düşünülmektedir.

\section{BULGULAR VE TARTIŞMA}

Kahramanmaraş ili şehir merkezinde 2012-2013 y1llarında meydana gelen yaralanmalı, ölümlü ve maddi hasarlı kazaların, kaza oluş yeri, kaza oluş zamanı ve arazinin topoğrafyasına göre incelenmesi yapılmıştır.
Kaza sebep ve sonuçlarına göre oluşturulan veri tabanından sorgulama ve analizler yapılarak kazaların meydana geldiği yerler tespit edilmiştir. Sorgulama sonuçları grafik ve öznitelik tabloları olarak haritalar üzerinde gösterilmiştir.

\section{2 ve 2013 Yıllarında Meydana Gelen Kazalar}

Veri setinde yapilan sorgulamalar sonucunda; 2012 yılında caddelerde 942, caddelere bağlı kavşaklarda 615 ve sokaklarda 237 kaza gerçekleşmiştir. 2013 y1lında ise caddelerde 980, caddelere bağlı kavşaklarda 548 ve sokaklarda 265 kaza gerçekleşmiştir (Şekil 2).

Şekil 2. 2012 ve 2013 yıllarında meydana gelen trafik kazaları

2012 ve 2013 y1llarında meydana gelen trafik kazalarının, Kahramanmaraş il merkezindeki cadde, kavşak ve sokakları dikkate alındığında, 202 caddede, 109 kavşakta ve 302 sokakta gerçekleştiği tespit edilmiştir. Aynı yerde 3' ten fazla gerçekleşen trafik kazaları, kaza kara noktası olarak tanımlanmıştır. Kahramanmaraş il merkezindeki cadde, kavşak ve sokaklarında gerçekleşen kazaların, kaza kara nokta sayısı tespiti yapılmış ve Çizelge 1'de gösterilmiştir.

Çizelge 1. 2012 ve 2013 y1llarına ait kaza kara noktaları

\begin{tabular}{|l|c|c|c|c|c|}
\hline Kaza Bölge Adı & $\begin{array}{c}\text { Kaza Gerçeklessen Bölge } \\
\text { Sayısı }\end{array}$ & $\begin{array}{c}\mathbf{2 0 1 2} \text { Kaza } \\
\text { Sayısı }\end{array}$ & $\begin{array}{c}\mathbf{2 0 1 3} \text { Kaza } \\
\text { Sayısı }\end{array}$ & $\begin{array}{c}\mathbf{2 0 1 2} \text { Kaza } \\
\text { Kara } \\
\text { Noktası }\end{array}$ & $\begin{array}{c}\mathbf{2 0 1 3} \text { Kaza } \\
\text { Kara Noktası }\end{array}$ \\
\hline CADDELER & 202 & 942 & 980 & 72 & 77 \\
\hline KAVŞAKLAR & 109 & 615 & 548 & 63 & 56 \\
\hline SOKAKLAR & 302 & 237 & 265 & 7 & 5 \\
\hline
\end{tabular}


Kahramanmaraş ili şehir merkezindeki kavşaklarda, 2012 yılında 615 kaza olmuş ve 63 kaza kara noktası bulunmaktadır. 2013 yılında ise 548 kaza olmuş ve 56 kaza kara noktası tespit edilmiştir. Kahramanmaraş il merkezindeki kavşaklarda meydana gelen bu kaza kara noktaların dağılımı Şekil 3'de gösterilmiştir.

Şekil 4, 5 ve 6'da, 2012-2013 y1lları arasındaki verilerin, kaza yoğunlukları açısından karşılaştırıldı ğ zaman benzer özellikler gösterdiği, özellikle 2013 yılındaki kaza yoğunluğu haritasında şehrin batı kısmında kaza yoğunluğunun arttığı gözlenmektedir. $\mathrm{Bu}$ durumun en önemli sebebi şehrin batı yönünde gelişiyor olması, üniversitenin batıya taşınması ve bat1 yönünde inşa edilen resmi kurumlar için açılan yeni yolların trafik yoğunluğunu artırdığ düşünülmektedir.

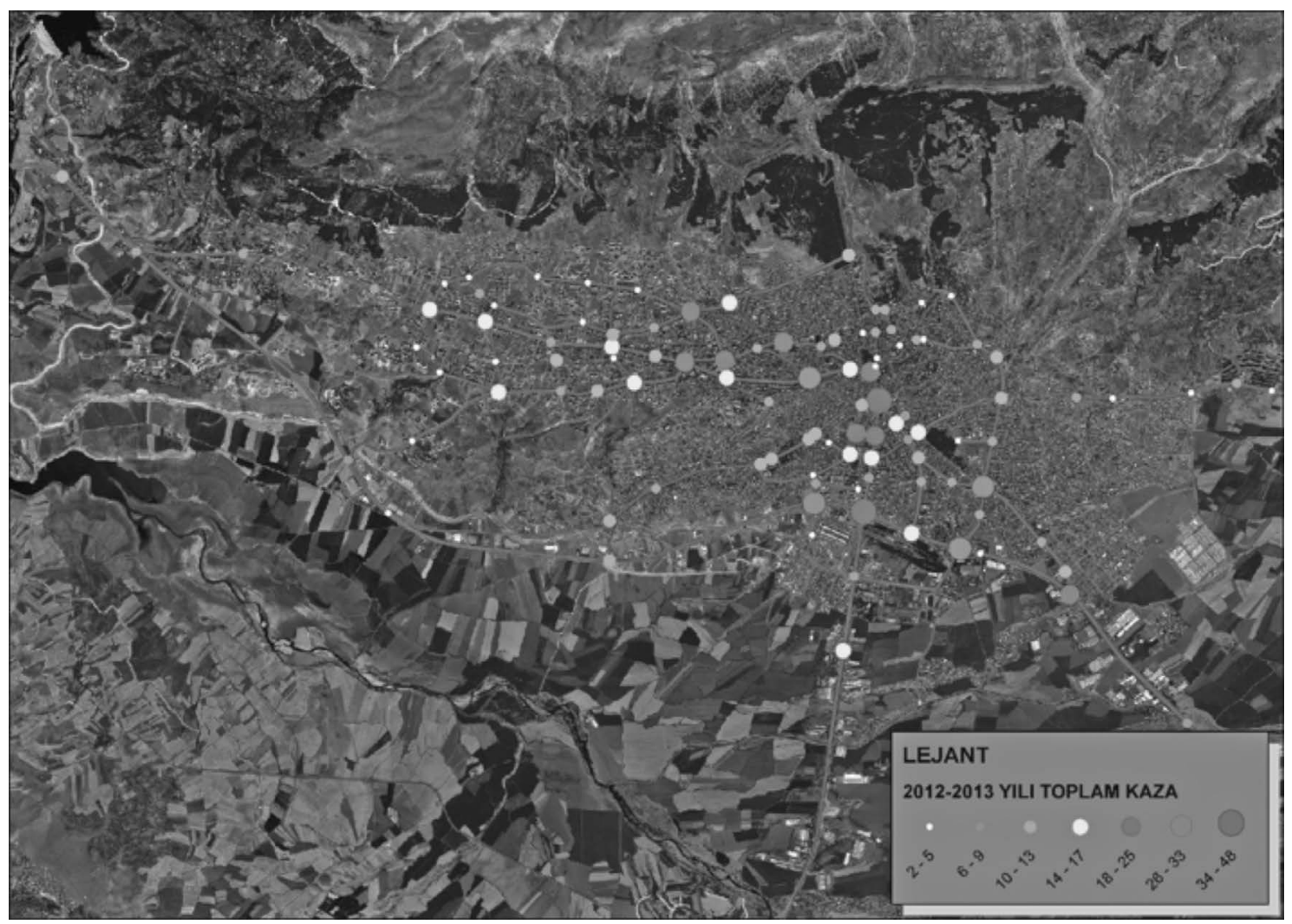

Şekil 3. 2012 ve 2013 yıllarına ait kavşaklarda meydana gelen kaza noktalarının dağılımı

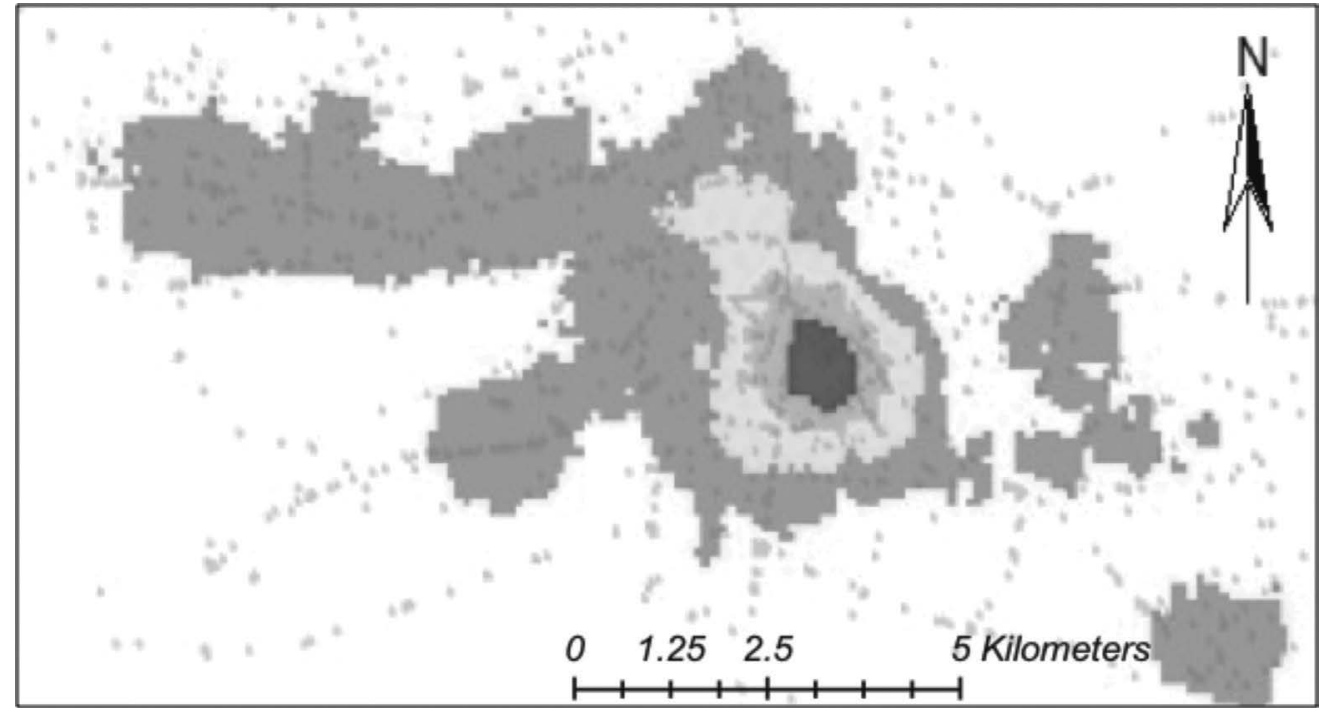

Şekil 4. 2012 yılında meydana gelen trafik kazalarının yoğunluk haritası 


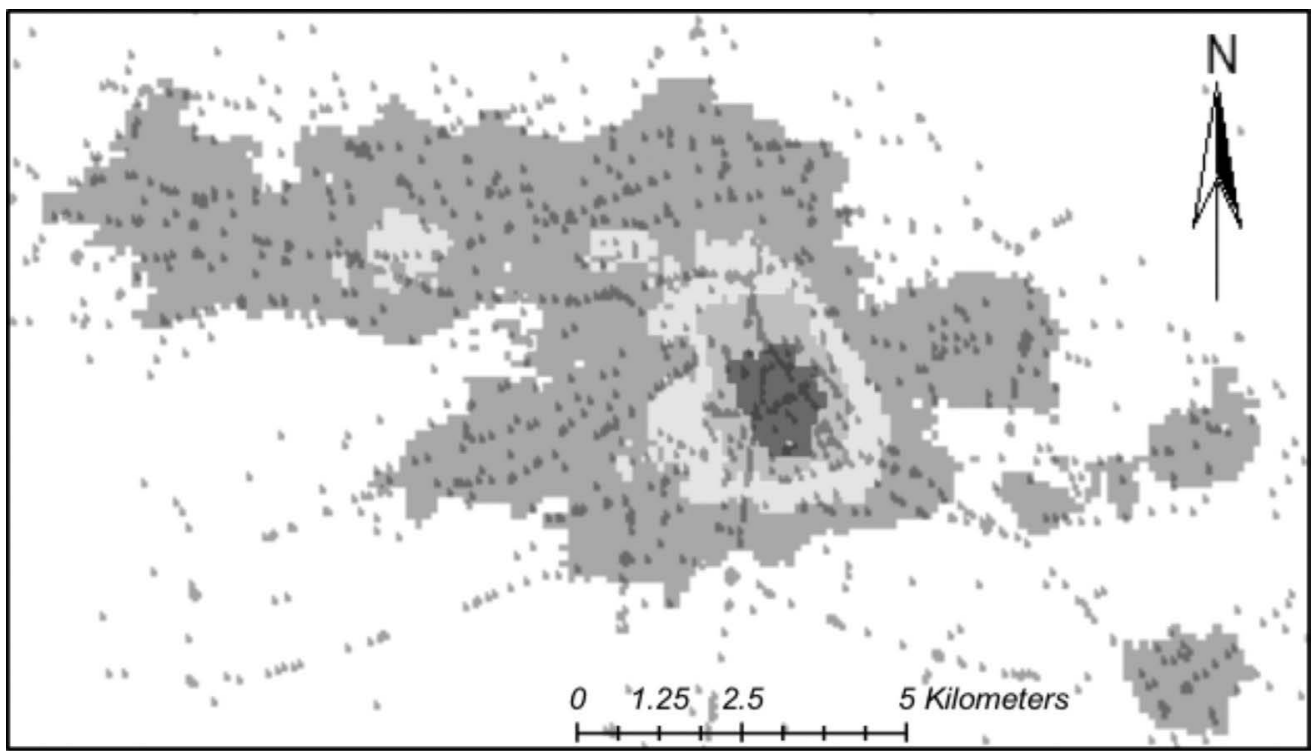

Şekil 5. 2013 yılında meydana gelen trafik kazalarının yoğunluk haritası
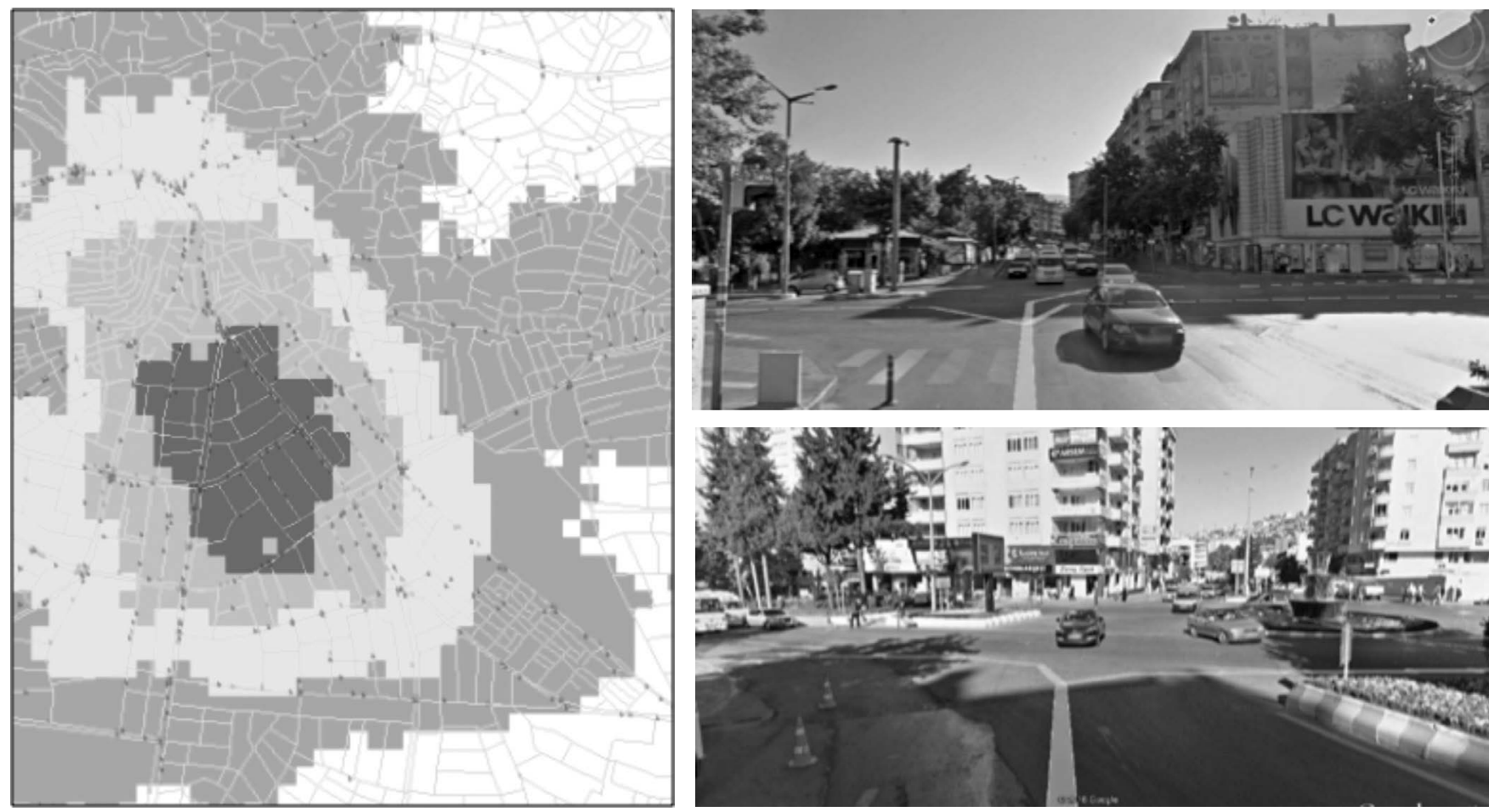

Şekil 6. Kaza yoğunluğu yüksek alanlar ve bu alanlara ait görüntüler (Hükümet Bulvarının Güneybatı ve Kuzeybatı yönünden görünümü)

\section{Kaza Oluşum Zamanına Göre Meydana Gelen Kazalar}

2012 yılında meydana gelen ölümlü kazaların \%29'u öğle vaktinde, \%57'si akşam vaktinde, \%14'ü ise yats1 vaktinde meydana gelmiştir. 2013 y1lında meydana gelen ölümlü kazaların ise \%33'ü öğle vaktinde, \% 67'si ise akşam vaktinde meydana gelmiştir. 2012 y1lında meydana gelen yaralanmalı kazaların ise; \%19’ u sabah vaktinde, \%31'i öğle vaktinde, \%39'u akşam vaktinde, \%8'i yatsı vaktinde, \%3'ü ise gece vaktinde meydana gelmiştir. 2013 yllında meydana gelen yaralanmalı kazaların ise, \%20'si sabah vaktinde, \%33'ü öğle vaktinde, \%36'sı akşam vaktinde, \%8'i yatsı vaktinde, $\% 4$ 'ü ise gece vaktinde meydana gelmiştir. 2012 ve 2013 yıllarında meydana gelen toplam trafik kazalarının gerçekleşme zamanlarına ait hazırlanan grafik Şekil 7'de gösterilmiştir. 
Vakitlere göre kaza sayıları

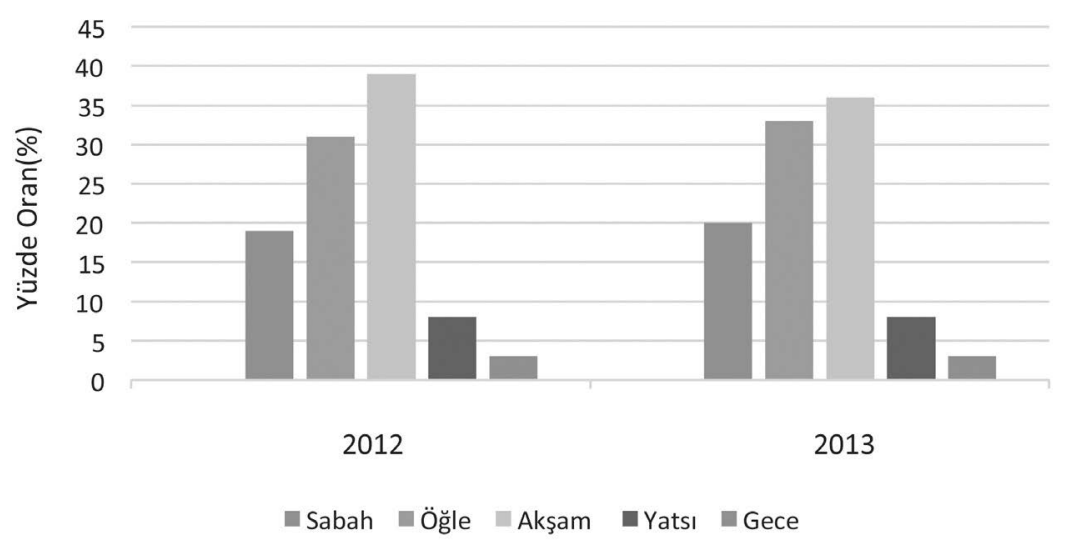

Şekil 7. 2012 ve 2013 yıllarında meydana gelen yaralanmalı trafik kazalarının gerçekleşme zamanına göre çizelgesi

\section{Trafik Kazaları için Topografik Yapısının İncelenmesi}

Kahramanmaraş ili yerleşim alanının topografik yapıs1, geçmişte gerçekleşen büyük depremlerden dolayı Ahir Dağı'nın eteğine kurulmuştur. $\mathrm{Bu}$ yüzden şehir merkezi engebelidir. Şehir merkezinin dışında kalan bölgeler düzlük olsa da geneli engebeli bir yapıya sahiptir. ArcGIS yazılımında Shuttle
Radar Topography Mission sayısal yükseklik verisi kullanılarak, Kahramanmaraş ili şehir merkezine ait eğim haritası oluşturulmuş ve harita üzerine trafik kaza noktaları eklenmiştir (Şekil 8). Elde edilen eğim haritası ile 2012 ve 2013 yıllarına ait kaza verileri üst üste getirilerek overlay analizi yapılmış ve eğim değer aralıklarındaki toplam kaza değerleri hesaplanmıştır (Çizelge 2).

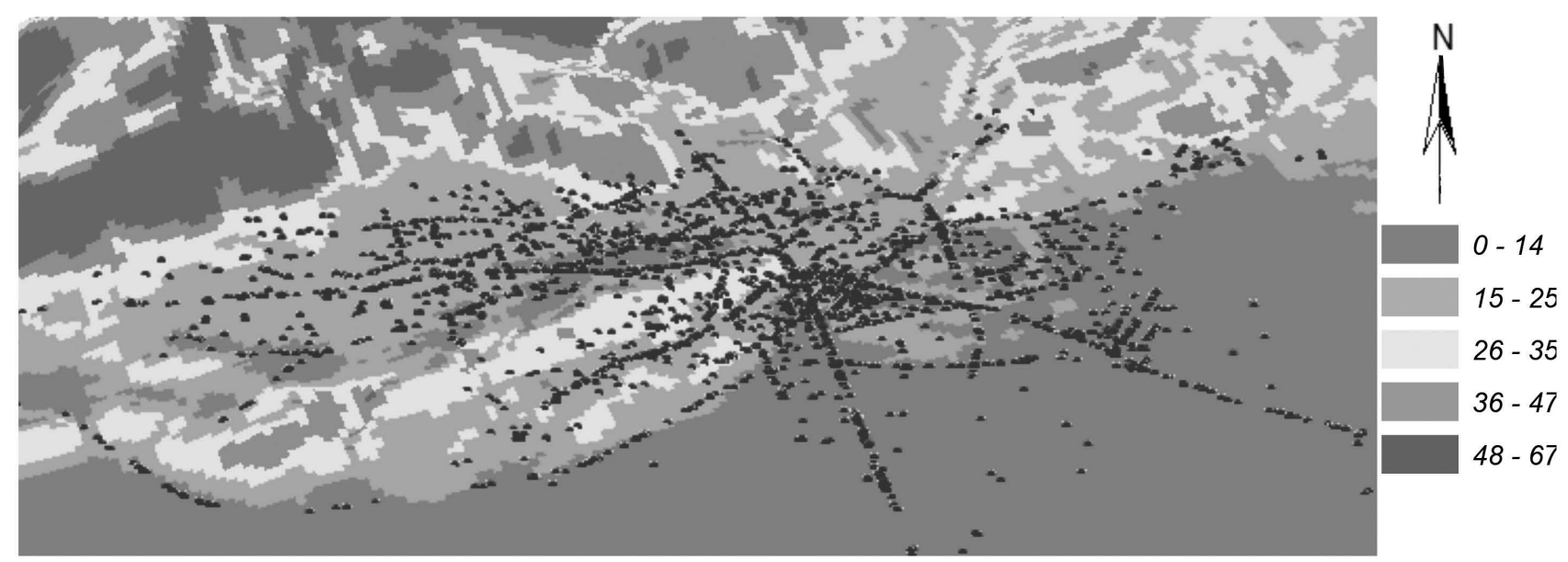

Şekil 8. Trafik kazalarının eğim haritası üzerinde gösterimi

Çizelge 2. Eğim haritası değer aralıklarındaki toplam kaza sayıları

\begin{tabular}{ccc}
\hline Eğim & \multicolumn{2}{c}{ Kaza Sayısı } \\
(Yüzde) & $\mathbf{2 0 1 2}$ & $\mathbf{2 0 1 3}$ \\
\hline $0-14$ & 1731 & 1701 \\
$15-25$ & 63 & 91 \\
$36-47$ & 0 & 1 \\
$48-47$ & 0 & 0 \\
\hline
\end{tabular}


Şekil 8 ve Çizelge 2'de görüleceği üzere, arazi eğimine bağlı olarak meydana gelen trafik kazalarının büyük bir bölümü \% 0-14 ve \%15-25 eğimli bölgelerde meydana gelmiştir. CBS ile yapılan trafik kaza analizlerinde, Kahramanmaraş ilinde 2012-2013 yıllarında meydana gelen yaralanmalı, ölümlü ve maddi hasarlı kazalar incelenmiştir. Yapılan istatistiksel araştırmalarda, trafik kazalarının en çok (17.00-22.00) saat aralığ tespit edilmiştir. Bunun sebebi olarak, çalışanların iş çıkışı yorgunluğu ile birlikte dikkat kaybının yaşanması ve yoğun trafik nedeniyle meydana gelen kazalardan dolay1 olduğu öngörülmektedir. Büyükşehir Belediyesi Trafik Koordinasyon Merkezince, bu saatler aralığında trafiğin yoğun olduğu bölgelerde, trafik akışının sağlanması için, trafik sinyalizasyon ayarlarında düzenleme yapılması gerektiği düşünülmektir.

\section{SONUÇ}

$\mathrm{Bu}$ çalışmada, trafik kaza analizlerinde CBS kullanımının önemi vurgulanarak bu teknolojinin kullanılmasıyla kaza analizlerinin incelenmesi yapılmıştır. CBS sayesinde trafik kazalarının azaltılması, trafik akışının sağlanması, ulaşım master planlarının ve arazi kullanım planlamalarının hazırlanması gibi işlemlerinin daha hızlı ve daha güvenilir şekilde yapılabileceği gösterilmiştir. CBS veri tabanındaki detaylı verilerle, kazaların analizlerinde daha önceden elde edilmeyen istatistiksel bilgilerin bu teknolojiler sayesinde üretilebileceği ve bunların da kazaların sebeplerini belirlemede etkili olacağ 1 görülmüştür. İl Emniyet Müdürlüğü'nden temin edilen kaza bilgi ve belgelerde konum (koordinat) bilgisinin bulunmaması, çalışmanın en büyük iş yükünü oluşturmuştur. Trafik kaza verilerinin Emniyet Müdürlüğ̈u'nce düzenli tutulmaması, kaza verilerinin düzenli olarak bilgisayar ortamına aktarılmaması, koordinat bilgilerinin alınmaması gibi temel problemler ileride yapılacak olan çalışmalar için sıkıntı olabileceği gibi mevcut çalışan sistemlerin de güncelleştirilmesini aksatacaktır. Emniyet Müdürlüğü tarafından oluşturulan trafik kaza tutanaklarında; karşılıklı çarpma, arkadan çarpma, yandan çarpma, duran araca çarpma, sabit cisme çarpma, yayaya çarpma, hayvana çarpma, araç devrilmesi, araçtan düşme vb. bilgilerin olmamasından dolayı, trafik kazalarının gerçekleşme sebepleri ile ilgili detaylı çalışma yapılamamıştır. $\mathrm{Bu}$ sebeple;
Emniyet Müdürlüğü'nün trafik kaza tutanaklarının tutulmasi esnasında bu türden bilgileri de kaydedilmesi ileri de yapılacak olan çeşitli analizler açısından son derece önemlidir. Ayrıca kurumun Büyükşehir Belediyesi ile koordineli çalıșılarak, KBS'nin Emniyet Müdürlüğü'nde kullanıma açılması ve kaza tutaklarının CBS'ye aktarılması konusunda koordinasyon sağlanmalıdır. Bunun için ortak bir çalışma ile trafik kazaları veri standardı tasarlanmalıdır. $\mathrm{Bu}$ standartlar sayesinde, CBS ortamında sorgulama ve analizler yapılarak doğru karar vermeyi kolaylaştıran sistemler oluşturulmalıdır.

\section{TEŞEKKÜR}

Bu çalışmada veri temini konusunda bizlere yardımcı olan Kahramanmaraş Büyükşehir Belediyesi İmar ve Şehircilik Daire Başkanlığı Harita Şube Müdürlüğü’ne ve Kahramanmaraş İl Emniyet Müdürlüğü'ne teşekkür ederiz.

\section{KAYNAKLAR}

Bek A, 2007. 2004 y1lında İstanbul - Ankara devlet yolunda meydana gelen ölümlü ve yaralamalı trafik kazalarının hava durumu, yol satıh durumu ve yoldaki yön durumuna bağlı olarak incelenmesi. Gazi Üniversitesi, Fen Bilimleri Enstitüsü Trafik Planlaması ve Uygulaması A.B.D., Yüksek Lisans Tezi, $130 \mathrm{~s}$.

Bensghir TK, Akay A, 2006. Bir kamu politika aracı olarak coğrafi bilgi sistemleri (CBS): Türkiye'de belediyelerin CBS uygulamalarının değerlendirilmesi. Çağdaş Yerel Yönetimler Dergisi, 15(1): 31-46.

Bilim A, 2006. Konya şehir içinde meydana gelen trafik kazalarının analizi ve kritik noktaların belirlenmesi. Selçuk Üniversitesi, Fen Bilimleri Enstitüsü İnşaat Mühendisliği Anabilim Dalı, $100 \mathrm{~s}$.

Büberci S, 1995. Trafik kazalarının oluşmasına etken olan faktörler, bunların saptanması ve çözüm önerileri. Gazi Üniversitesi Fen Bilimleri Enstitüsü, Yüksek Lisans Tezi, 1-25 s.

Camkesen N, 1998. Trafik kaza analizleri ve tahmin modelleri Yıldız Teknik Üniversitesi, Fen Bilimleri Enstitüsü, Doktora Tezi, 1-6 s

Çiçek M, 2007. Trafik bilgi sistemi verileri Ankara ili trafik güvenliğinin incelenmesi. Gazi Üniversitesi, Fen Bilimleri Enstitüsü Trafik Planlaması ve Uygulaması A.B.D. Yüksek Lisans Tezi, $68 \mathrm{~s}$.

Çodur MY, Tortum A, Çodur M, 2013. Erzurum north ring road accident prediction model with generalized linear regression. Iğdır Üniversitesi Fen Bilimleri Enstitüsü Dergisi, 3(1): 79-84.

Erdogan S, 2003. Afyon ili girişimcilik profilinin coğrafi bilgi sistemleri ile analizi. Bilişim Günleri, Pamukkale Üniversitesi, 17-19 Nisan 2003, Denizli. 
Erdoğan S, Yılmaz İ, Baybura T, Güllü M, 2008. Geographical Information System aided traffic accident analysis system case study city of Afyonkarahisar. Accident Analysis \& Prevention, 40(1): 174-181.

Ertunc E, Mutluoglu O, Cay T, 2013. Intersection road accident analysis using geographical information systems: Antalya (Turkey) example. Application of Information and Communication Technologies (AICT) 7th International Conference on Date of Conference, 23-25 Oct. 2013, Bakü.

Foote EK, Lynch M, 1996. Georaphic Information Systems as an integrating technology: context, concepts and definations. The Geographer's Craft Project, Department of Geograpy, University of Texas at Austin.

Geymen A, Yomralığlu T, 2006. Yerel yönetimler için devingen yapılı bir kent bilgi sistemi yazılımının geliştirilmesi: DEVKBS. YvKB'06-Yapı ve Kentte Bilişim Kongresi, 8-9 Haziran 2006, Ankara.

Gündoğdu G, 2010. Coğrafi bilgi teknolojileri kullanılarak trafik kaza analizi: Adana örneği. Çukurova Üniversitesi Fen Bilimler Enstitüsü, Yüksek Lisans Tezi.

Kahramangil M, Şenkal Ş, 1999. Kaza kara noktaları belirleme yöntemleri. II. Ulaşım ve Trafik Kongresi, Sergisi Bildiriler Kitab1, 119-128.

Karaşahin M, Terzi S, 2002. Determination of Hazardous locations on highways through GIS: A Case Study of Isparta-Antalya. International Symposium on GIS, İstanbul.

Korkmaz Y, 2005. Türkiye karayollarında meydana gelen trafik kazalarının çoklu regresyon analizi ile modellenmesi. Kırıkkale Üniversitesi Fen Bilimleri Enstitüsü, Yüksek Lisans Tezi.
Mandloi D, Gupta R, 2003. GIS as an aid to identify accident patterns. Map India Conference, GISdevelopment.net.

Mirasyedi F, 2006. Mevsimlerin Türkiye'deki trafik kazalarına etkisinin incelenmesi ve kaza tahmin modelleri. Kırıkkale Üniversitesi, Fen Bilimleri Enstitüsü, İnşaat Anabilim Dalı, Yüksek Lisans Tezi, $85 \mathrm{~s}$.

Özgan E, 2007. Bolu Dağı dahil D-100 devlet karayolu kesiminin çok yönlü klinik incelenmesi ve kaza kara noktalarının belirlenmesi sonuç raporu. Düzce Üniversitesi, Bilimsel Araştırma Projeleri Başkanlığı.

Özgan E, 2008. Karayolu araç tipi ve şekli ile kaza sonuçlar arasındaki ilişkileri analizleri. Gazi Üniversitesi Mühendislik Mimarlık Fakültesi Dergisi, 3(1), 97-104.

Saplığlu M, Karaşahin M, 2006. Coğrafi Bilgi Sistemi yardımı ile Isparta ili kent içi trafik kaza analizi. Pamukkale Üniversitesi Mühendislik Bilimleri Dergisi, 12(3): 321-332.

Söylemezoğlu T, 2006. Coğrafi Bilgi Sistemleri ile trafik kaza analizi: Ankara örneği. Gazi Üniversitesi, Fen Bilimleri Enstitüsü Trafik Planlaması ve Uygulaması A.B.D., Yüksek Lisans Tezi, 105s.

Tortum A., Çodur M.,Y., Kılınç B., 2012. Modelling traffic accidents in Turkey using regression analysis. Iğdır Üniversitesi Fen Bilimleri Enstitüsü Dergisi, 2(3): 69-78.

Tuncuk M, 2004. Coğrafi Bilgi Sistemi yardımıyla trafik kaza analizi: Isparta örneği. Süleyman Demirel Üniversitesi, Fen Bilimleri Enstitüsü, İnşaat Anabilim Dalı, Yüksek Lisans Tezi, $80 \mathrm{~s}$. 